JURNAL SEKRETARIS \& ADMINISTRASI BISNIS

Jurnal homepage http/ljurnal asmtbac id/index php/jsab

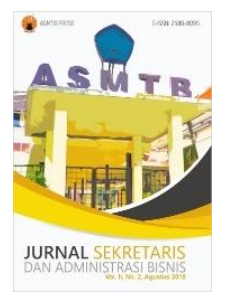

\title{
Traders' Preference in Choosing Expedition Partner in Tanah Abang Market
}

\section{Preferensi Pedagang Pasar Tanah Abang dalam Memilih Jasa Ekspedisi}

Sukmadi $^{1}$, Wahyu Teri Aripin ${ }^{2}$, and Nuslih Jamiat ${ }^{3}$

${ }^{1}$ Sekolah Pasca Sarjana STP NHI Bandung, ${ }^{2}$ Prodi Teknik Industri STT Cipasung, ${ }^{3}$ Prodi Administrasi Bisnis

Politeknik LP3I Bandung

12ads.sukmadi@stp-bandung.ac.id, ${ }^{2}$ wahyu@ @ttcipasung.ac.id, ${ }^{3}$ nuslihjamiat@plb.ac.id

\section{ARTICLE INFO}

Article history:

Received 15th March 2018

Received in revised form 16th July 2018

Accepted 18th August 2018

\section{Keywords:}

Traders,

Expedition Partner,

Market

\begin{abstract}
Choosing expedition partner has been becoming a crucial issue for those who are running retail business in this digital era. Having the right partner in expedition to work with can be another competitive advantage for the company itself. In this era, almost every transaction would be done online, therefore the meeting between sellers and buyers is no longer neseccary in some cases; but still the trust between them must be maintained. Choosing the right expedition is one of the ways to maintain that trust. The right expedition partner here will be defined as those expedition company who can guarantee to deliver product faster (on schedule), cheaper for the service price and also easy to be contacted. Tanah Abang itself is the biggest market in Jakarta. This place has been chosen as the object for the research, because the seller here is actively selling product both offline and online. Descriptive approach has been used for the research methodology. Data are generated from questionnaire and interview. All datas that have been gathered will show the number of seller or trader who is actively purchase expedition services in a week. Besides that, it is cleared seen which and why such expedition company leading the market.
\end{abstract}

\section{Pendahuluan}

Berdasarkan data dari Asosiasi Logistik dan Forwarder Indonesia (ALFI), Pertumbuhan Compound Annual Growth Rate (CAGR) pada interval 2013 hingga 2017 sebesar 11,7\%. Sementara volatilitas freight forwarding mencapai 11,8\%. Kemudian, express and small parcel mencapai $21,7 \%$. Dibandingkan dengan Singapura CAGR contract logistics-nya hanya sebesar 7,3\%. Filipina 11,3\%, dan Thailand 9,7\%. Hal ini menjadikan volatilitas Indonesia tertinggi se-ASEAN. Kondisi ini secara tidak langsung, menggambarkan bahwa paradigma pasar jasa logistik mulai beralih ke dalam negeri.

Beberapa tahun terakhir, kontestasi antar penyedia layanan jasa kurir semakin berkembang dengan kondisi persaingan antar-provider yang semakin ketat. Salah satu mekanisme yang digunakan untuk melihat output kontestasi antar penyedia jasa kurir bisa di lihat dari hasil survei Top Brand Award di interval tahun 2015 sampai 2017. 
Indikator hasil survei berasal dari tiga parameter yakni top of mind share, top of market share, dan top of commitment share. Dalam tiga tahun terakhir, JNE menjadi juara jasa kurir dengan Top Brand Index pada tahun 2015 sebesar 43,5\%, tahun 2016 sebesar 47,6\% dan tahun 2017 berada pada 49,4\%.

Sementara beberapa provider lain seperti TIKI dan jasa kurir POS masing-masing hanya mendapatkan 34,9\% dan 7,9\% untuk Top Brand Index pada tahun 2017. Di sisi lain DHL sebagai penyedia layanan yang telah mengglobal juga masuk dalam Top 4 produk. Meskipun berfokus pada distribusi logistik atau kargo dengan kuantitas besar, DHL masih mendapatkan persentase yang baik dalam layanan pengiriman ekspres yang dilakukannya. Persentase tiga tahun terakhir memang cenderung turun yaitu dari 2,1\% pada tahun 2015 ke arah 1,3\%. Akan tetapi, DHL masih mampu menarik minat pengguna layanan pengiriman ekspres di tengah persaingan yang ketat dan didominasi oleh JNE dan diikuti TIKI. PT. Pos Indonesia yang merupakan perusahaan jasa kurir tertua di Indonesia milik BUMN, tertinggal oleh perusahaan swasta baru seperti JNE dan TIKI.

Menurut Asosiasi Perusahaan Jasa Pengiriman Ekspress Pos dan Logistik Indonesia (Asperindo), pada kuartal pertama tahun 2017, volume jasa pengiriman telah tumbuh sekitar 14,7\%. Jika dibanding tahun 2016, terjadi peningkatan intensitas perdagangan 5,7 kali lipat (iDEA dan Taylor Nelson Sofres). Asperindo menargetkan pertumbuhan industri logistik ini rata-rata 14-15\% pertahun, dengan patokan nilai pasar pada tahun 2016 sebesar Rp. 50 triliun. Sejalan dengan itu, JNE juga menyatakan terlihat peningkatan signifikan pada tiap tahunnya. Pada tahun 2013 dan 2014, JNE telah melaksanakan jasa pengiriman barang rata-rata sebanyak 6 juta dan 8 juta kiriman per bulan. Sedangkan pada tahun 2015, rata-rata jumlah pengiriman barang mencapai 12 juta per bulannya. Pada tahun 2016 menunjukkan kenaikan sebesar 30\% dibanding tahun sebelumnya dengan jumlah pengiriman hingga 16 juta kiriman dalam sebulan.

Untuk kembali dapat merebut hati konsumen, PT. Pos Indonesia perlu menyusun kembali atau memodifikasi strategi perusahaan yang sudah dijalankan. Supaya dapat menentukan strategi yang tepat, maka ada data-data yang harus dikumpulkan. Salah satunya adalah data perkembangan kondisi pasar. Data perkembangan kondisi pasar yang dimaksud adalah kepuasan pelanggan serta ekspektasiekspektasinya terhadap layanan jasa kurir.

Untuk mendapatkan data tersebut, menurut Kotler (2008: 140) salah satunya adalah dengan metode survey. Selain untuk mendapatkan data kepuasan dan harapan pelanggan, dengan survey dapat diketahui juga tentang nilai pembelian dan kemungkinan konsumen untuk merekomendasikan merek kepada konsumen lain.

Salah satu tempat potensial untuk dilakukan survey perkembangan bisnis jasa kurir adalah di pusat perdagangan di Indonesia khususya di kota-kota besar. Untuk survey perkembangan kondisi pasar dipilih Pasar Tanah Abang, karena pasar tersebut merupakan pusat perbelanjaan terbesar di Jakarta.

Sekilas tentang Pasar Tanah Abang. Pasar Tanah Abang yang dulu dikenal dengan Pasar Sabtu berdiri sejak tahun 1735. Yustinus Vinck adalah sosok yang dikenal sebagai pendiri pasar perdagangan ini atas izin dari Gubernur Jenderal Abraham Patramini. Perputaran uang di Tanah Abang kembali hidup di abad ke-20, ketika saudagar China dan Arab banyak bermukim di Tanah Abang yang dikembalikan peruntukannya sebagai pasar oleh Belanda. Tahun 1881, Pasar Tanah Abang berangsur pulih. Pasar mulai dibuka dua hari yakni Sabtu dan Rabu.

Perkembangan dari tahun ke tahun kawasan Pasar Tanah Abang tumbuh cukup pesat dengan ribuan pedagang yang hadir berjualan di sana. Pasar tersebut kini buka setiap hari Senin hingga Minggu. Waktunya sendiri mulai pagi hingga sore hari. Bangunan pasar pun nampak lebih mewah, dengan adanya perbaikan gedung di setiap bloknya juga hadir gedung bertingkat yang cukup tinggi. Tak hanya itu, seperti halnya Pasar Tanah Abang Metro, Blok A, dan Blok B telah dilengkapi dengan 
fasilitas AC. Pasar Tanah Abang terbagi menjadi tiga wilayah, yaitu Tanah Abang Metro, Tanah Abang Lama dan Tanah Abang AURI. Tanah Abang Lama terdiri dari beberapa blok, antara lain blok A, B dan F. Sementara Tanah Abang AURI memiliki blok yang lebih banyak, yaitu A, B, C, D, E, F, G, AA, BB dan CC. Perputaran uang di salah satu blok tekstil di pasar tanah abang mencapai Rp. 30 Triliun pada tahun 2016.

Berdasarkan informasi dari pihak pengelola gedung Blok B Tanah Abang yaitu Bapak Iman Sumantri selaku Operational Manager mengatakan, saat ini volume penjualan ritel di Blok B Tanah Abang tetap stabil dan tidak terpengaruh dengan maraknya bisnis online. Alasannya, karena kawasan pusat belanja ini mempunyai keunggulan sebagai pusat fashion terlengkap.

Menurutnya pengunjung yang datang ke Blok B Tanah Abang bisa mencapai 80.000 dalam sehari. Kebanyakan dari mereka, kata Iman, berasal dari luar kota dan luar negeri. "Angka penjualan Blok B Tanah Abang tetap besar dan setiap hari selalu ramai pengunjung," ujarnya. Saat ini, kata dia, Blok B Tanah Abang memiliki 5.000 toko dengan okupansi 80 persen. "Kebanyakan pedagang Blok B Tanah Abang juga menjalankan bisnis online dan offline, sehingga keduanya saling melengkapi," jelasnya. Iman mengatakan, kawasan pusat belanja ini masih menjadi pusat fashion dan grosir terbesar di ASEAN. Bahkan Bapak Presiden Joko Widodo (Jokowi) selalu membawa tamu negara untuk belanja di tempat ini. "Intinya, Blok B Tanah Abang masih menjadi pusat bisnis dan perputaran uang," pungkasnya.

\section{Kajian Literatur}

\section{Pasar di Era Digital}

Secara umum perbedaan mendasar dari pasar konvensional dengan pasar digital adalah cara berkomunikasi. Berikut beberapa contoh pasar di era digital, diantaranya:

1. Auction Store: Tempat untuk memberikan pelayanan dalam bidang perdagangan. Misalnya untuk pengiklanan produk perusahaan, cara pembayaran dan sebagainya. Contoh : www.ebay.com, www.swinde.com.

2. Online Store : Tempat untuk menjual atau membeli secara digital dengan memilih, memesan barang lewat internet tanpa harus bertatap muka dengan penjual secara langsung. Contoh : www.Amazon.com, www.tokopedia.com, www.bhineka.com.

3. Online Service : Tempat untuk meminta informasi dan service lain dari perusahaan dengan cepat dan mudah atau dapat melakukan proses jual beli, misalnya jasa tiket perjalanan, jasa service dan lain-lain. Contoh: ww.wotif.com, www.airasia.com, www.blizmegaplex.com.

4. Other Service : Layanan yang menyediakan fasilitas untuk penjualan produk dan jasa diluar klasifikasi yang telah dijabarkan sebelumnya. Contoh : www.kaskus.us, www.facebook.com. (Nugroho, 2016:18-19)

Di Pasar Tanah Abang sendiri sekarang sedang mengalami proses peralihan dari cara berbisnis konvensional ke digital. Salah satu indikatornya, para pedagang Pasar Tanah Abang mulai membuka toko secara virtual (toko online). Hal tersebut berdampak pada berubahnya pola logistik pada Pasar Tanah Abang. Salah satu diantaranya adalah frekuensi pengiriman barang semakin tinggi, dengan jumlah atau volume setiap pengiriman yang relative kecil dan jumlah tujuan pengiriman yang meningkat. Hal tersebut juga berimplikasi pada tingkat penggunaan jasa ekspedisi yang semakin tinggi.

\section{Logistik}

Menurut Martin Christopher, seorang professor marketing dan logistic, dalam bukunya Logistic and Supply Chain Management, berpendapat bahwa: Logistik adalah proses dari pengolahan secara strategis dalam usaha memperoleh, pergerakan dan penyimpanan bagian material dan persediaan akhir, juga berhubungan dengan arus informasi, melalui organisasi dan jalur pemasarannya adalam 
beberapa cara untuk mendapatkan keuntungan tertentu di masa depan yang maksimal melalui ongkos pepemunahan pemesanan yang efektif.

Definisi Logistik menurut Council of Logistic Management, adalah : Logistik melibatan proses perencanaan, implementasi, dan pengendalian agar didapat suatu efisiensi aliran biaya dan kefektifan proses penyipanan bahan mentah, bahan setengah jadi, barang jadi dan informasi-informasi yang berhubungan, dari asal ke titik konsmsi dengan tujuan memenuhi kebutuhan konsumen. (Hendayani, 2011:17-18). Tujuan dan Misi Logistik : Inti dalam suatu tujuan ataupun misi logistic adalah pendistribusian yang harus dilakukan pada waktu, tempat dan cara yang tepat (Hendayani, 2011:17$18)$.

\section{Memilih Partner Logistik}

Lima faktor terpenting dalam pemilihan partner dalam bidang transportasi dan logistik, diantaranya:

a) Kecepatan; Kecepatan waktu yang dibutuhkan untuk menyelesaikan suatu pendistribusian atau pengantaran dari satu titik ke titik lainnya yang telah ditentukan.

b) Keamanan; Keamanan dari barang atau produk yang dipindahkan dalam proses pengantaran menjadi perhatian khusus dari pihak konsumen atau pihak yang menggunakan jasa transportasi. Tentunya para konsumen menginginkan barang atau produk yang mereka ingin kirimkan atau terima masih dalam keadaan baik atau tidak rusak atau ada yang hilang ketika sampai ditujuan.

c) Biaya; Biaya yang terlibat dalam proses transportasi adalah biaya yang harus dikeluarkan ketika dilakukan pengangkutan barang mulai dari proses pengepakan untuk jaminan keamanannya terlebih dahulu hingga biaya-biaya selama perjalanan seperti bahan bakar dan lainnya hingga biaya jasa dari pengantarnya itu sendiri.

d) Perjanjian; Perjanjian antara pihak yang mengantarkan dengan pihak konsumen yang menunggu produknya yang diminta sampai. Dimana di dalamnya terdapat komitmen dari pihak pemasok yang mengirimkan produk atau bahan mentah yang dipesan bisa sampai dengan tepat waktu, dengan kondisi yang sesuai dengan yang diinginkan konsumen yaitu dalam keadaan tidak rusak atau ada bagian yang hilang.

e) Jasa; Jasa yang diberikan ketika proses dalam system logistik dapat berupa pelayanan dari si pengantar sesuai dengan perjanjian dan pemberian jasa tambahan seperti halnya bonus biaya jasa mengepak barang atau produk, sehingga tidak dibebankan kepada pihak konsumen. Setiap perusahaan mengharapkan suatu pelayanan yang terbaik diharapkan dengan tidak menambah biaya transportasi dari biaya yang normal, sehingga kita harus bisa memikirkan cara agar harapan tersebut tercapai dengan cara dapat mengantarkan barang dengan kondisi barang yang tetap seperti mulanya tidak terjadi kerusakan. (Hendayani, 2011:97-100)

\section{Metodologi Penelitian}

Untuk mencapai tujuan penelitian mengenai perkembangan kondisi pasar di Pasar Grosir Blok B Tanah Abang, metode penelitian yang digunakan adalah metode penelitian deskriptif. Metode ini digunakan karena dalam penelitian ini hanya berupaya untuk menggambarkan dan mengungkap beberapa hal berikut, yaitu: profil pedagang, produk yang dijual, jenis pelanggan, wilayah penjualan, media sosial dan toko online yang digunakan, dampak penggunaan media digital terhadap penjualan, frekuensi dan gramasi pengiriman per minggu, rata-rata omzet per bulan, ekspedisi yang digunakan untuk pengiriman barang, dan alasan pemilihan ekspedisi.

Jenis dan sumber data yang digunakan dalam penelitian ini adalah data primer yang diperoleh langsung melalui survei lapangan. Klasifikasi sumber data digambarkan dalam table 1. 
Tabel 1.

Jenis dan Sumber Data

\begin{tabular}{|c|c|c|c|}
\hline No. & Jenis Data & Sumber Data & Kategori Data \\
\hline 1 & $\begin{array}{l}\text { Profil Pasar Grosir Blok A } \\
\text { Tanah Abang }\end{array}$ & Pengelola Gedung & Data Primer \\
\hline 2 & Profil Pedagang & Pedagang & Data Primer \\
\hline 3 & Produk yang Dijual & Pedagang & Data Primer \\
\hline 4 & Jenis Pelanggan & Pedagang & Data Primer \\
\hline 5 & Wilayah Penjualan & Pedagang & Data Primer \\
\hline 6 & Media Sosial yang Digunakan & Pedagang & Data Primer \\
\hline 7 & Toko Online yang Digunakan & Pedagang & Data Primer \\
\hline 8 & $\begin{array}{l}\text { Frekuensi Pengiriman Barang } \\
\text { per Minggu }\end{array}$ & Pedagang & Data Primer \\
\hline 9 & $\begin{array}{l}\text { Rata-rata Gramasi Pengiriman } \\
\text { per Minggu }\end{array}$ & Pedagang & Data Primer \\
\hline 10 & Rata-rata Omzet per Bulan & Pedagang & Data Primer \\
\hline 11 & Ekspedisi yang Digunakan & Pedagang & Data Primer \\
\hline 12 & Alasan Pemilihan Ekspedisi & Pedagang & Data Primer \\
\hline
\end{tabular}

Jumlah responden yang disurvei sebanyak 506 responden yang dipilih secara random. Jumlah ini dianggap cukup dengan dasar jumlah minimal sampel untuk penelitian survey adalah 100. (Sekaran: 2009)

Teknik pengumpulan data menggunakan metode wawancara, kuesioner dan dokumentasi. Kegiatan wawancara dilaksanakan bersamaan dengan pengisian kuesioner. Sehingga jawaban yang diperoleh dari responden dapat lebih dipertanggung jawabkan. Sedangkan dokumentasi adalah penelaahan dokumen-dokumen baik yang ada di lokasi survei maupun dari studi pustaka lainnya.

Penyajian dan interpretasi data mengacu pada metode yang dikembangkan oleh Sugiyono (2010: 29) yakni menggunakan tabel. Adapun untuk proses analisis akan didasarkan sepenuhnya pada hasil interpretasi data yang bersifat kuantitatif yang didapat dari kuesioner yang sebelumnya sudah ditabulasikan.

\section{Hasil dan Diskusi}

Pusat Grosir Blok B Tanah Abang dibangun diatas lahan 1,2 hektar, dengan luas bangunan 163 ribu meter persegi (m2) terdiri dari $5.162 \mathrm{kios}$, dan dirancang sebagai pusat grosir yang modern dengan berbagai macam fasilitas yang membuat nyaman dan aman bagi penjual dan pengunjung.

Berdasarkan informasi dari bapak Sriwijaya (Hr \& GA Manager) tingkat hunian di Blok B Tanah Abang mencapai 90\%, dimana seluruh pedagang terdistribusi di 10 lantai berdasarkan zona-nya masing-masing.

Adapun pembagian lantai dan zona dijelaskan pada tabel 2.

Tabel 2.

Lantai dan Zoning

\begin{tabular}{|c|l|l|}
\hline No. & Lantai & Zoning \\
\hline 1 & Lantai Basement 2 (B2) & Tekstil/Kebaya \\
\hline 2 & Lantai Basement 1 (B1) & $\begin{array}{l}\text { Tekstil Grosir, Gordign, Bedcover, } \\
\text { Sprei, dan kerudung }\end{array}$ \\
\hline 3 & Lantai Semi Lower Ground (SLG) & Fashion Busana Muslim \\
\hline 4 & Lantai Lower Ground & Busana Wanita Dewasa \\
\hline
\end{tabular}




\begin{tabular}{|c|l|l|}
\hline No. & Lantai & Zoning \\
\hline 5 & Lantai Ground $(\mathrm{G})$ & Baju Anak dan Jeans \\
\hline 6 & Lantai 1 & Fashion Remaja dan Anak \\
\hline 7 & Lantai 2 & Busana Pria \\
\hline 8 & Lantai 3 & Baju Kaos, Jacket dan Baju Sport \\
\hline 9 & Lantai 3A & Aksesories \& Perdagangan on line \\
\hline 10 & Lantai 5 & $\begin{array}{l}\text { Perbankan dan Fashion Busana } \\
\text { Muslim }\end{array}$ \\
\hline
\end{tabular}

Dari hasil wawancara dan pembagian kuesioner dapat diuraikan data sebagai berikut:

Berdasarkan produk utama yang dijual:

Produk utama yang dijual oleh Pedagang di Pasar Grosir Blok B Tanah Abang adalah pakaian muslim wanita (94 responden - 18.58\%) dan pakaian casual wanita (71 responden - $14.03 \%$ ). Pedagang memasarkan produk baik ke konsumen akhir maupun konsumen bisnis secara berimbang 50-50\% (176 responden $-34.78 \%$ ). Mayoritas pedagang memiliki cakupan wilayah penjualan utama di seputaran Jabodetabek (283 responden - 55.93\%) dan Sumatra (80 responden - 15.81\%).

Tabel 3.

Wilayah Penjualan Utama Pedagang

\begin{tabular}{|l|c|c||l|c|c|}
\hline Wilayah & $\begin{array}{c}\text { Jumla } \\
\mathbf{h}\end{array}$ & $\mathbf{\%}$ & Wilayah & $\begin{array}{c}\text { Jumla } \\
\mathbf{h}\end{array}$ & $\mathbf{\%}$ \\
\hline Jabodetabek & $\mathbf{4 0 9}$ & $\mathbf{3 4 . 1}$ & Papua & 33 & 2.75 \\
\hline Jabar & 134 & $\begin{array}{c}11.1 \\
\mathbf{4}\end{array}$ & Sulawesi & 103 & 8.60 \\
\hline Jateng & 45 & 3.76 & Kalimantan & 156 & $\begin{array}{c}13.0 \\
2\end{array}$ \\
\hline Jatim & 51 & 4.26 & Sumatra & $\mathbf{1 8 2}$ & $\begin{array}{c}\mathbf{1 5 . 1} \\
\mathbf{9}\end{array}$ \\
\hline Bali, Lombok, dsk. & 20 & 1.67 & Lainnya & 65 & 5.43 \\
\hline
\end{tabular}

Berdasarkan metode komunikasi dengan pelanggan:

Metode komunikasi dengan pelanggan berimbang antara offline dan online, yaitu 50-50\% (167 responden - 33.00\%). Media sosial WhatsApp merupakan media yang paling dominan digunakan oleh para pedagang (461 responden - 91.83\%). Dari total 506 responden ternyata mayoritas (384 responden) tidak menggunakan toko online dan sisanya (122 responden) menggunakan toko online dalam memasarkan produknya ke pelanggan. Adapun toko online utama yang digunakan untuk memasarkan produk adalah Shopee (54 responden - 44.26\%) dan Tokopedia (31 responden $25.41 \%$ ). Dengan alasan penggunaan media toko online utama yang beragam, yaitu banyak konsumen (26 responden $-20.47 \%$ ) dan banyak pengunjung (19 responden $-14.96 \%$ ).

Berdasarkan pandangan responden terhadap media digital:

Penggunaan media digital memberikan dampak positif terhadap penjualan, hal tersebut dapat dilihat dimana mayoritas pedagang memilih jawaban meningkat (363 responden $-71.74 \%$ ).

Berdasarkan frekuensi penggunaan jasa kurir setiap minggunya:

Frekuensi pengiriman barang ke pelanggan setiap minggunya mayoritas pedagang memilih frekuensi $>4$ kali pengiriman per minggu (158 responden $-31.23 \%$ ). 
Tabel 4.

Frekuensi Pengiriman Barang Menggunakan Jasa Ekspedisi

\begin{tabular}{|l|c|c||lc|c|}
\hline Frekuensi & Jumlah & $\mathbf{\%}$ & Frekuensi & $\begin{array}{c}\text { Jumla } \\
\mathbf{h}\end{array}$ & $\mathbf{\%}$ \\
\hline$\leq 1 \mathrm{kali}$ & 103 & 20.36 & 4 kali & 39 & 7.71 \\
\hline $2 \mathrm{kali}$ & 101 & 19.96 & $>4$ kali & $\mathbf{1 5 8}$ & $\mathbf{3 1 . 2 3}$ \\
\hline 3 kali & 105 & 20.75 & & & \\
\hline
\end{tabular}

Dari tabel 4 dapat disimpulkan bahwa sekitar $80 \%$ pedagang di pasar Tanah Abang aktif mengirimkan barang dagangannya menggunakan jasa ekspedisi.

Berdasarkan gramasi penggunaan jasa kurir setiap minggunya:

Mayoritas pedagang menyatakan bahwa rata-rata gramasi pengiriman per minggu selama tahun 2017 adalah lebih $<25 \mathrm{Kg}$ (238 responden - 47.04). Pedagang secara umum memiliki rata-rata Omzet per bulan adalah lebih kecil dari Rp. 200 juta (388 responden $-76.68 \%$ ).

Tabel 5.

Gramasi Pengiriman Barang

\begin{tabular}{|l|c|c||l|c|c|}
\hline $\begin{array}{l}\text { Rata-rata } \\
\text { Gramasi }\end{array}$ & $\begin{array}{c}\text { Jumla } \\
\text { h }\end{array}$ & $\begin{array}{l}\text { Rata-rata } \\
\text { Gramasi }\end{array}$ & $\begin{array}{c}\text { Jumla } \\
\text { h }\end{array}$ & \% \\
\hline$<25 \mathrm{Kg}$ & 238 & $\begin{array}{c}47.0 \\
4\end{array}$ & $76-100 \mathrm{Kg}$ & 38 & 7.51 \\
\hline $26-50 \mathrm{Kg}$ & 100 & $\begin{array}{c}19.7 \\
6\end{array}$ & $>100 \mathrm{Kg}$ & 66 & $\begin{array}{c}13.0 \\
4\end{array}$ \\
\hline $51-75 \mathrm{Kg}$ & 64 & $\begin{array}{c}12.6 \\
5\end{array}$ & & & \\
\hline
\end{tabular}

Dari tabel 5 diketahui sebagian besar pedagan di Tanah Abang mengirim barang dengan gramasi kecil.

Berdasarkan jasa ekspedisi yang digunakan:

Dalam melakukan pengiriman barang ke pelanggan, pedagang banyak menggunakan jasa ekspedisi utama dari PT JNE (262 responden - 51.78\%) dan CARGO (146 responden - 28.85).

Tabel 6.

Ekspedisi Utama yang Digunakan

\begin{tabular}{|l|c|c||l|c|c|}
\hline $\begin{array}{l}\text { Ekspedisi yang } \\
\text { Digunakan }\end{array}$ & Jumlah & $\mathbf{\%}$ & $\begin{array}{l}\text { Ekspedisi yang } \\
\text { Digunakan }\end{array}$ & Jumlah & \% \\
\hline JNE & $\mathbf{2 6 2}$ & $\begin{array}{c}\mathbf{5 1 . 7} \\
\mathbf{8}\end{array}$ & Genesis & 0 & 0.00 \\
\hline J\&T & 28 & 5.53 & CARGO & $\mathbf{1 4 6}$ & $\mathbf{2 8 . 8 5}$ \\
\hline SICEPAT & 3 & 0.59 & Pandu Logistik & 0 & 0.00 \\
\hline Pos Indonesia & 2 & 0.40 & Lion Parcel & 5 & 0.99 \\
\hline Wahana & 11 & 2.17 & Lainnya & 49 & 9.68 \\
\hline
\end{tabular}

Dari tabel 6 diketahui bahwa JNE mendapatkan porsi terbesar sebagai ekspedisi utama dalam pengiriman produk ke pelanggan. Adapun PT. Pos Indonesia menduduki peringkat ke 5 di bawah CARGO, J\&T dan SICEPAT.

Berdasarkan alasan memilih ekspedisi:

Alasan utama menggunakan ekspedisi utama di atas adalah mudah dijangkau (163 responden $32.21 \%$ ), pengiriman barang yang cepat \& tepat waktu (104 responden $-20.55 \%$ ), dan harga yang ditawarkan kompetitif (97 responden - 19.17\%). 


\section{Simpulan}

Dari hasil analisis dan pengolahan data yang telah dilakukan diketahui bahwa xekitar $80 \%$ pedagang pasar secara aktif menggunakan jasa eskpedisi lebih dari satu kali setiap minggunya. Total berat barang yang dikirimkan setiap minggunya relatif kecil. Artinya para pedagang mengirimkan barang dalam jumlah kecil namun dengan frekuensi yang relatif sering. JNE menduduki peringkat pertama sebagai ekspedisi utama yang digunakan dalam pengiriman barang ke konsumen. Sebanyak 51,78\% pedagang memilih JNE sebagai ekspedisi utamanya. Disusul oleh CARGO sebanyak 28,85\%, dan J\&T sebanyak 5,53\%. Sementara PT. POS Indonesia hanya mendapatkan porsi sebanyak $0,4 \%$. Ada 11 alasan yang mendasari pemilihan jasa ekspedisi yang digunakan. Dari kesebelas alasan, tiga terbesar adalah mudah dijangkau sebesar $32,21 \%$, pengiriman barang yang cepat dan tepat waktu sebesar $20,55 \%$ serta harga yang kompetitif sebesar $19,17 \%$.

\section{Referensi}

AMMPS. (2017). Sejarah Tanah Abang. Retrieved from Kompas Travel: http://travel.kompas.com/read/2017/11/09/182000327/sejarah-tanah-abang-dari-kebunpalem-hingga-pusat-grosir.

Fauzi, Y. (2017). Perubahan Pola Belanja Masyarakat Bukan Alasan Daya Beli Lesu. Retrieved from cnnindonesia Ekonomi: https://www.cnnindonesia.com/ekonomi/20170803163656-92232260/perubahan-pola-belanja-

Gunawan, H. (2017). Logistik Indonesia Tertinggi di Asean. Retrieved from Retrieved from tribun bisnis: https://economy.okezone.com/read/2016/09/13/320/1487876/pertumbuhan-e-moneymasih-minim

Kotler, P. (2008). Manajemen Pemasaran, Edisi 12 (Jilid 2). Jakarta: Indeks

Kotler, P. (2009). Manajemen Pemasaran, (Edisi 13). Jakarta; Erlangga.

Ramadhan, B. (2016). Jumlah Ponsel di Indonesia Melebihi Jumlah Populasi. Retrieved from: https://www.goodnewsfromindonesia.id/2016/01/21/data-terbaru-ternyata-jumlah-ponsel-diindonesia-melebihi-jumlah-populasi

Sekaran, U. (2009). Research Methods for Business: Metodologi Penelitian Untuk Bisnis. (Edisi 4 Buku 1) Jakarta: Salemba Empat.

Sugiyono. (2010). Metode Penelitian Pendekatan Kuantitatif, Kualitatif dan R\&D. Bandung: Alfabeta.

Suriasumantri, J. S. (2001). Filsafat Ilmu: Sebuah Pengantar Populer, Pustaka Sinar Harapan: Jakarta.

Ramadhan, B. (2016). Jumlah Ponsel di Indonesia Melebihi Jumlah Populasi. Retrieved from: https://www.goodnewsfromindonesia.id/2016/01/21/data-terbaru-ternyata-jumlah-ponsel-diindonesia-melebihi-jumlah-populasi 